\title{
OPTIMIZATION OF FUSED DEPOSITION MODELING PROCESS PARAMETERS FOR MATERIAL CONSUMPTION AND MANUFACTURING TIME
}

DOI : 10.36909/jer.ICIPPSD.15539

\author{
Shrikrishna Pawar*, Sarfraz Ali Quadri, Dr. Dhananjay Dolas \\ Department of Mechanical Engineering, Jawaharlal Nehru Engineering College, MGM \\ University, Aurangabad, India \\ *Email: shrikrishnapawar@jnec.ac.in; Corresponding author
}

\begin{abstract}
This paper aims to explore the effect of layer thickness, infill density and build orientation on the material consumption and manufacturing time of specimens printed by the fused deposition modeling process. Specimens in accordance with ASTM Standards were printed by varying the process parameters such as layer thickness, infill density and build orientation. Time required to manufacture the part and amount of material consumed during the process are recorded. Increase in infill density results into increase in material consumption and manufacturing time. Layer thickness and build orientation also impacts manufacturing time and material consumption respectively. With increased application of FDM process, determining the process parameter to decrease the material consumption and manufacturing time shall help the FDM practitioners globally. Present work elucidates the optimization of FDM process parameters to achieve minimum material consumption and manufacturing time.
\end{abstract}

Keywords: Optimization, Response Surface Methodology (RSM), Fused Deposition Modeling (FDM), Additive Manufacturing (AM)

\section{INTRODUCTION}

Modern production systems demand quicker product development with least possible iterations and lead time. Additive manufacturing, interchangeably termed as 3D printing or rapid prototyping process, are addressing the need of modern production systems by developing the parts quickly. In early phase of development of additive manufacturing, these processes have limited application in the field of prototyping only. But with advent of new technology and materials, additive manufacturing has spread its wings in numerous fields such as aerospace 
industry, defense industry, medical fields, architectural and construction industry etc. (Gibson 2015)

Ease in operation and maintenance of 3D printing machines, lesser requirement of supervision, rapid material change, low cost and negligible post processing making additive manufacturing a preferable choice for product development. Complex parts are also possible to manufacture without additional tooling requirement. (Chadha 2019)

Fused deposition modeling is one of the most important types of additive manufacturing process. FDM process involves manufacturing of part through layer-by-layer deposition of material on the build platform. Generally, FDM printer consists of an extruder used for converting filament into extrudate by means of heat addition through heater coils. Extruder with apt sized nozzle follows the path for depositing the material in the form of layer onto build platform inside the building chamber. Nozzle path is in accordance with the sliced layer determined by the software with reference to input CAD file of the part. (Pawar 2020).

In FDM process, parts of same geometry with similar materials, but manufactured at different values of process parameters will results into building of parts with different properties (Sood, Panda 2009, and Pawar 2019). Shailesh Raj purohit (2008) established the relationship between performance parameters of PLA parts manufactured by FDM. Effect of process parameters which includes rastor width, layer height, rastor width, and rastor angle on tensile strength is studied. Furthermore, effect of these process parameters on fracture surfaces has been investigated. Krishna Motaparti et al. (2017) conducted experiments to analyze the influence of air gap, build direction, and rastor angle on flexural strength of Ultem specimens built by FDM. Vishwas M. et al. (2018) identified impact of model orientation, thickness of shell and layer on tensile strength and dimensional accuracy of Nylon and ABS materials. Mechanical properties of these materials' FDM parts are highly affected by orientation angle and shell thickness. Wadia Ameen et al. (2021) conducted performance assessment of fused deposition modeling process for investigating geometric and dimensional accuracy of different geometric profiles.

\section{METHODOLOGY}

Material used for this work was PC-ABS. The specimens as depicted in Figure 1, prepared for the flexural testing in accordance with ASTM D790 were utilized for recording the material 
consumption and manufacturing time. The Specimen CAD model was prepared by using the SOLIDWORKS software. This CAD model in .stl file format was used as an input to FDM printer M200 of make ZORTRAX. Technical specification of this printer is summarized in Table 1. All specimens were printed on the same printer with $0.4 \mathrm{~mm}$ diameter nozzle. Selection of process parameter and its values were based upon the prior research work and trial tests. Process parameters and its values are shown in Table 2. Total 18 samples were manufactured at different settings of the process parameters. All experiments were designed in accordance with full factorial design of experiments methodology. Full factorial experiments cover all possible combinations of process parameters in each replication of the experiments.

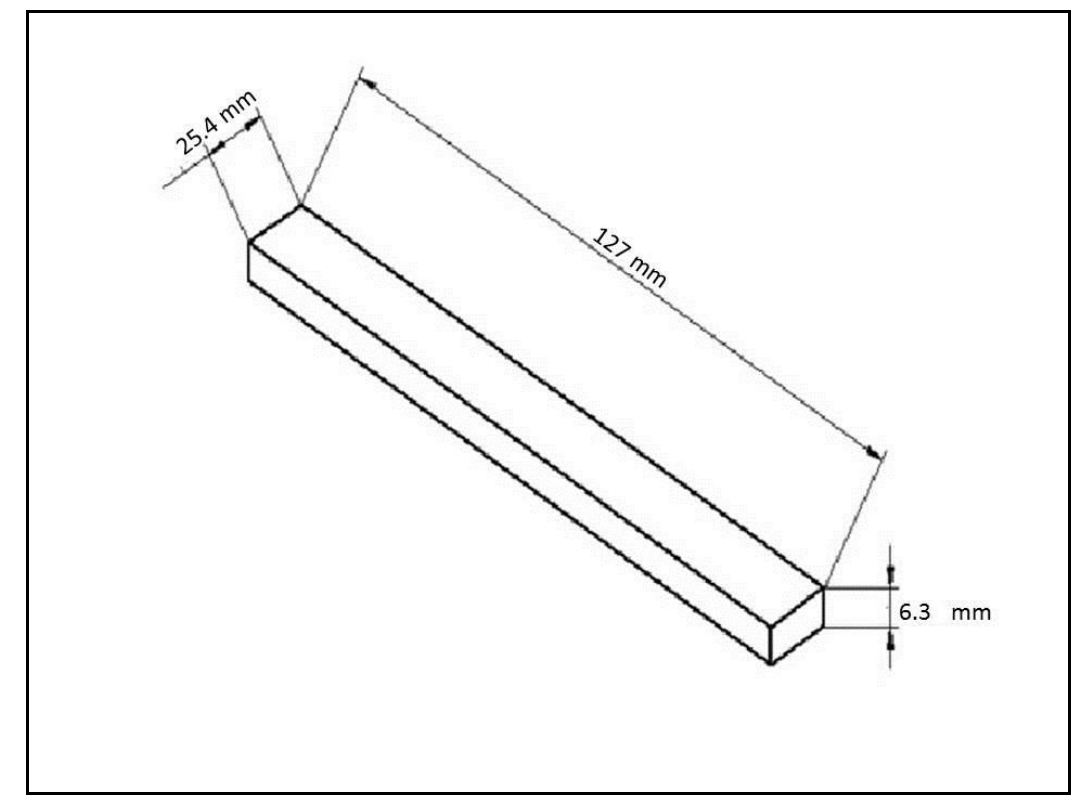

Figure 1. Geometric Details of Specimen

Table 1: Printer Specification

\begin{tabular}{|l|l|}
\hline \multicolumn{1}{|c|}{ Printer } & \multicolumn{1}{c|}{ Specification } \\
\hline Make and Model & Zortrax M 200, Zortrax S.A. Poland \\
\hline Build volume & $200 \times 200 \times 180 \mathrm{~mm}$ \\
\hline Diameter of Material & $1.75 \mathrm{~mm}$ \\
\hline Diameter of Nozzle & $0.4 \mathrm{~mm}$ \\
\hline
\end{tabular}


Maximum temperature (extruder)

Maximum temperature (platform) $290^{\circ} \mathrm{C}$

$105^{\circ} \mathrm{C}$

Table 2. Process Parameter Variations

\begin{tabular}{|l|c|c|c|c|}
\hline & Symbol & \multicolumn{3}{|c|}{ Values } \\
\hline Layer Thickness (mm) & LT & 0.14 & 0.19 & 0.29 \\
\hline Infill Density (\%) & ID & 20 & 60 & 100 \\
\hline Build Orientation & BO & Horizontal & -- & Vertical \\
\hline
\end{tabular}

\section{RESULTS AND DISCUSSION}

Figure 2 demonstrates the actual specimens printed by FDM process and Table 3 shows results of each experiment along with process parameter setting.

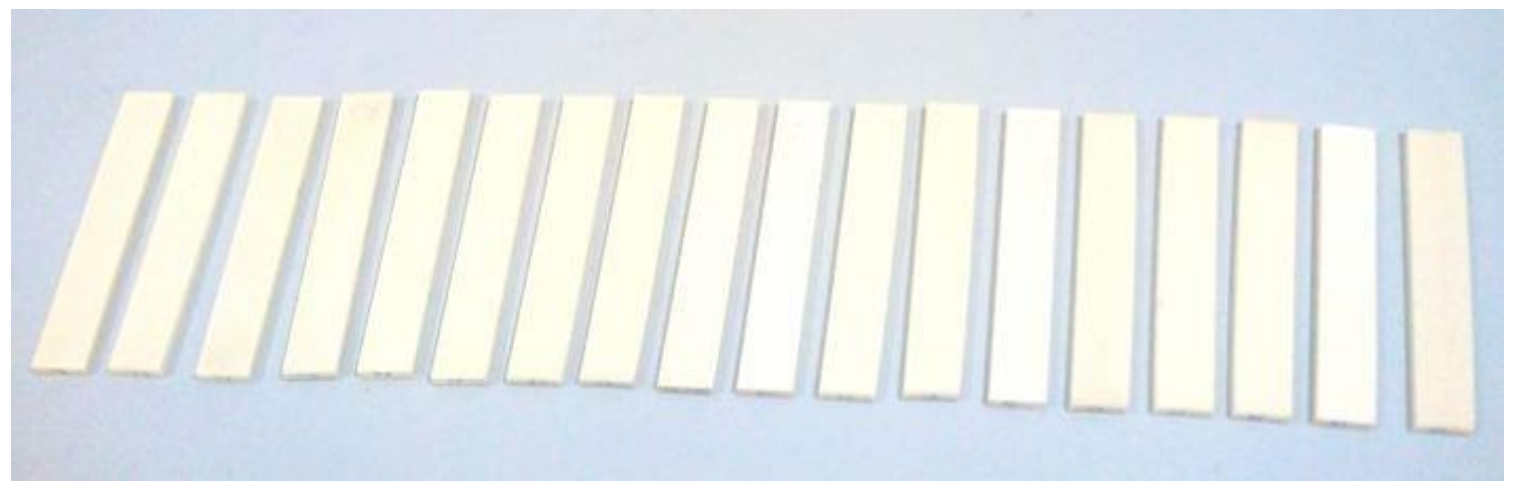

Figure 2 Printed Specimens

Table 3 Results of Experimental Runs

\begin{tabular}{|c|c|c|c|c|c|}
\hline $\begin{array}{c}\text { Run } \\
\text { Order }\end{array}$ & LT (mm) & ID (\%) & BO & MC (g) & MT (Minute) \\
\hline 1 & 0.29 & 60 & Horizontal & 26 & 78 \\
\hline
\end{tabular}




\begin{tabular}{|c|c|c|c|c|c|}
\hline 2 & 0.14 & 20 & Vertical & 17 & 107 \\
\hline 3 & 0.29 & 20 & Horizontal & 23 & 70 \\
\hline 4 & 0.29 & 100 & Horizontal & 30 & 117 \\
\hline 5 & 0.19 & 60 & Horizontal & 25 & 104 \\
\hline 6 & 0.14 & 20 & Horizontal & 19 & 95 \\
\hline 7 & 0.29 & 60 & Vertical & 22 & 74 \\
\hline 8 & 0.29 & 100 & Vertical & 27 & 124 \\
\hline 9 & 0.14 & 100 & Horizontal & 32 & 221 \\
\hline 10 & 0.14 & 60 & Horizontal & 25 & 121 \\
\hline 11 & 0.29 & 20 & Vertical & 17 & 63 \\
\hline 12 & 0.19 & 60 & Vertical & 22 & 103 \\
\hline 13 & 0.19 & 20 & Horizontal & 20 & 85 \\
\hline 14 & 0.19 & 100 & Vertical & 28 & 186 \\
\hline 15 & 0.19 & 20 & Vertical & 17 & 85 \\
\hline 16 & 0.14 & 60 & Vertical & 22 & 131 \\
\hline 17 & 0.19 & 100 & Horizontal & 32 & 178 \\
\hline 18 & 0.14 & 100 & Vertical & 28 & 239 \\
\hline
\end{tabular}

\section{A. Results for Material Consumption}




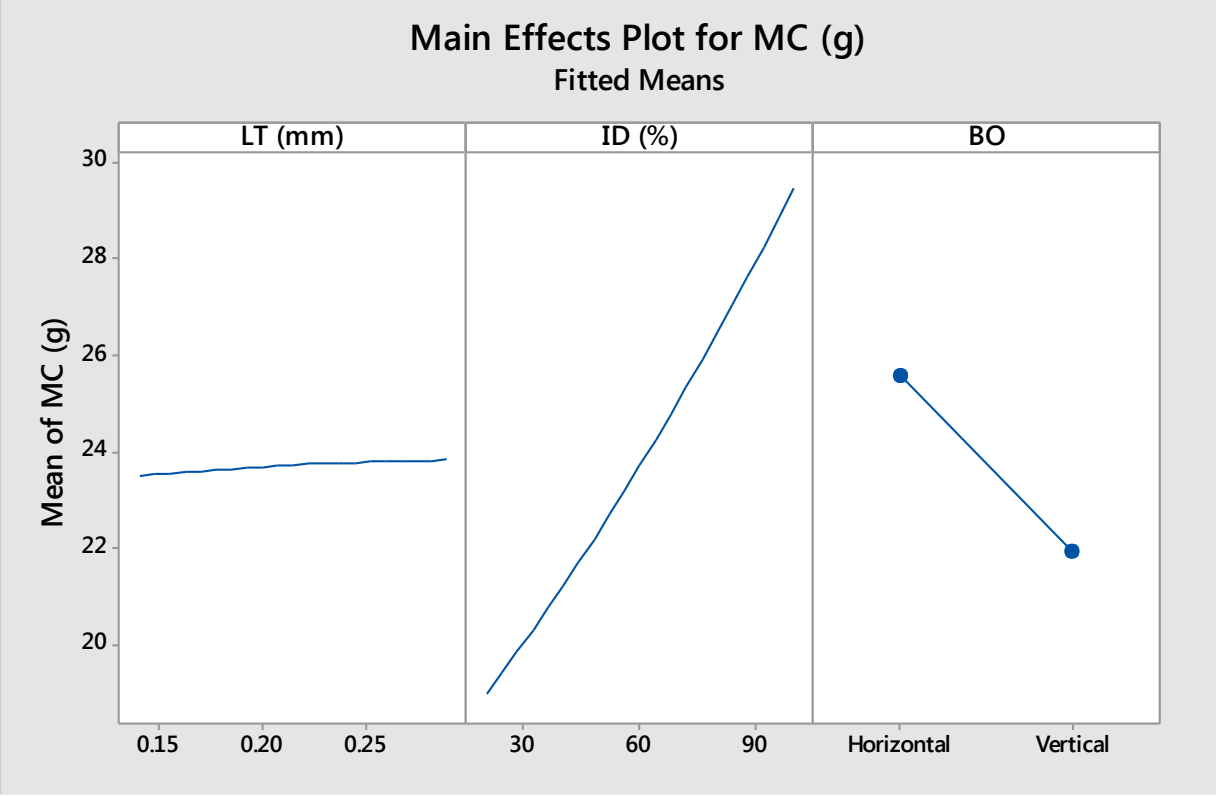

Figure 3. Main Effect Plot for Material Consumption

Figure 3 represents that material consumption increases when infill density increases, it means less material is consumed when lower infill density is selected. This is due to the fact that low infill density means sparse structure of specimens will be produced which consumes less material. On the other hand, high infill density means thick structure. At $100 \%$ infill density, complete solid structure of specimen will be produced which consumes more material.

It is also found that material consumption decreases when specimens are manufactured with vertical build orientation instead of horizontal build orientation. It is because of the fact that perimeter will be less for vertical build orientation as compared to horizontal build orientation.

Analysis of variance (ANOVA) is used for analyzing the obtained results which aids in predicting the significance of selected process parameters. Table 4 summarizes the results of ANOVA for material consumption.

Table 4 ANOVA for Material Consumption

\begin{tabular}{|c|c|c|c|c|c|}
\hline Source & DF & Adj SS & Adj MS & F-Value & P-Value \\
\hline LT & 2 & 0.333 & 0.167 & 0.16 & 0.853 \\
\hline ID & 2 & 342.333 & 171.167 & 165.05 & 0.000 \\
\hline BO & 1 & 56.889 & 56.889 & 54.86 & 0.000 \\
\hline Error & 12 & 12.444 & 1.037 & & \\
\hline Total & 17 & 412.000 & & & \\
\hline
\end{tabular}


F-Value of the process parameter indicates impact of respective process parameter on the performance variable. It is evident from the Table 4 that infill density with F-Value of 165.05 making big impact on material consumption, followed by the impact through build orientation. It also shows that impact of infill density is significantly higher than the other process parameters, followed by build orientation and layer thickness is not statistically significant.

\section{B. Results for manufacturing Time:}

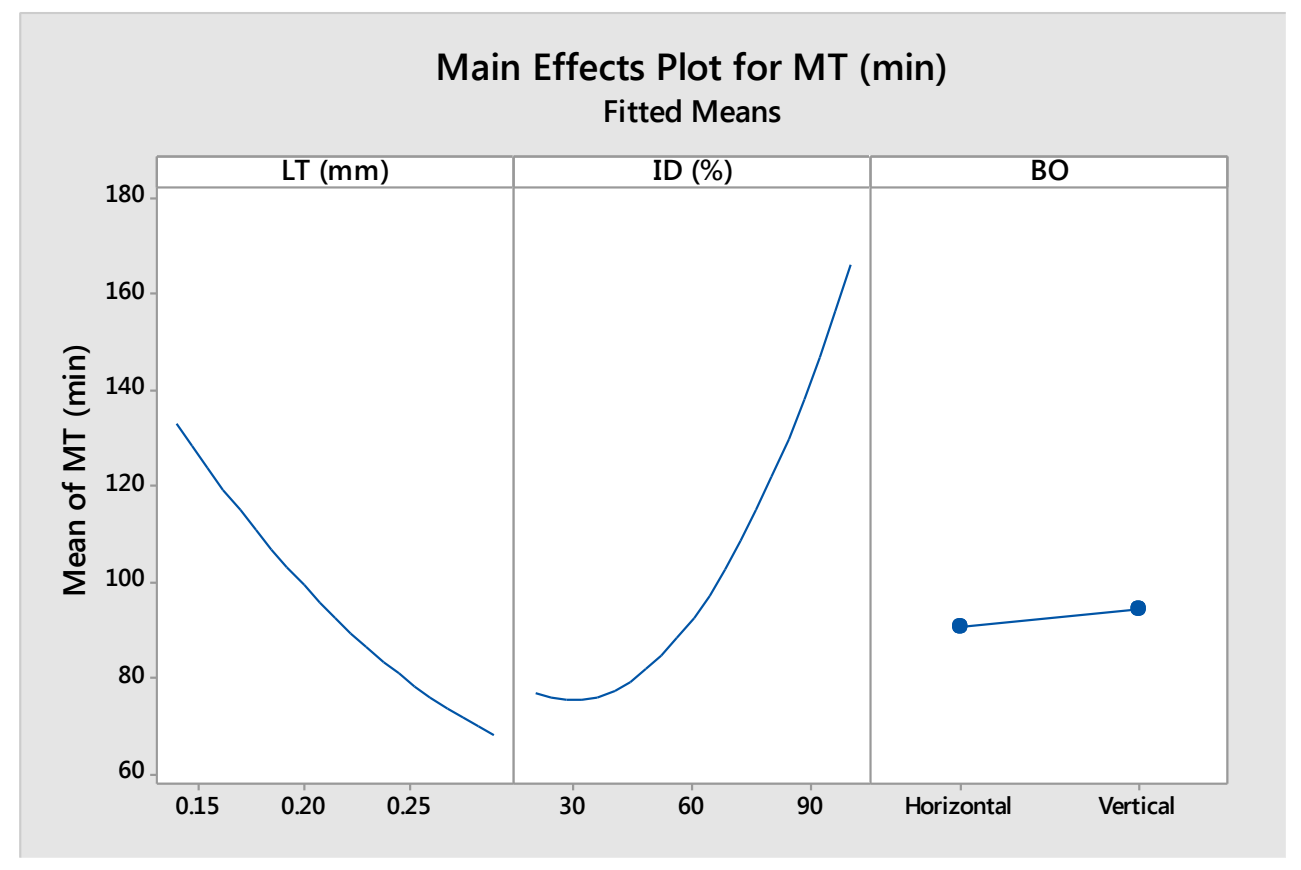

Figure 4 Main Effect Plot for Manufacturing Time

Figure 4 represents that manufacturing time decreases when layer thickness increases, it means less time is required when higher layer thickness is selected. This is due to the fact that lower layer thickness means specimen will be build with thinner layer deposition and for building the specimen, more number of layers needed to be deposited which will take more time. On the other hand, higher layer thickness means specimen will be build with less number of layers due to thicker layers, which obviously will take less time for deposition.

It is also evident from the Figure 4 that manufacturing time increases with increase in infill density. Increase in manufacturing time is due to the fact that more infill density means denser structure, which will be required more material deposition resulting in more time for building the specimen. 
Table 5 ANOVA for Manufacturing Time

\begin{tabular}{|c|c|c|c|c|c|}
\hline Source & DF & Adj SS & Adj MS & F-Value & P-Value \\
\hline LT & 2 & 12594.3 & 6297.2 & 22.04 & 0.000 \\
\hline ID & 2 & 29497.3 & 14748.7 & 51.63 & 0.000 \\
\hline BO & 1 & 102.7 & 102.7 & 0.36 & 0.560 \\
\hline Error & 12 & 3428.1 & 285.7 & & \\
\hline Total & 17 & 45622.5 & & & \\
\hline
\end{tabular}

Table 5 summarizes the results of ANOVA for manufacturing time. It is evident that infill density with F-Value of 51.63 making big impact on manufacturing time, followed by the impact through layer thickness. It also shows that impact of infill density is significantly higher than the other process parameters, followed by layer thickness and build orientation is not statistically significant.

\section{Multi-objective optimization:}

On the basis of above discussion, Table 6 represents the significance of process parameters for the different output variable such as material consumption and manufacturing time.

Table 6 Statistical Significance of Process Parameters

\begin{tabular}{|c|c|c|c|c|}
\hline S. No. & $\begin{array}{c}\text { Process } \\
\text { Parameter }\end{array}$ & Symbol & $\begin{array}{c}\text { Material } \\
\text { Consumption }\end{array}$ & $\begin{array}{c}\text { Manufacturing } \\
\text { Time }\end{array}$ \\
\hline 1 & Layer Thickness & LT & -- & Significant \\
\hline 2 & Infill Density & ID & Significant & Significant \\
\hline 3 & $\begin{array}{c}\text { Build } \\
\text { Orientation }\end{array}$ & BO & Significant & -- \\
\hline
\end{tabular}

From Table 6 it is evident that different process parameters are significantly influencing the each output variable, this necessitate the optimized setting of process parameters for satisfying the multi objective of reducing the material consumption and manufacturing time. Weight of material consumption and manufacturing time are kept equal considering the same importance of both these output variables. Response surface methodology is utilized for optimizing the process parameters.

Table 7 Optimum Set of Process Parameter

S. No. Process Parameter Symbol Optimum Value 


\begin{tabular}{|c|c|c|c|}
\hline 1 & Layer Thickness & LT & 0.2582 \\
\hline 2 & Infill Density & ID & 20 \\
\hline 3 & Build Orientation & BO & Vertical \\
\hline
\end{tabular}

Optimum set of process parameters for achieving the best possible values of output variables are represented in Table 7 . The predicted values of material consumption and manufacturing time are 17.58 grams and 69.29 minutes respectively.

\section{CONCLUSION}

In this work, FDM process is used for manufacturing the test specimens by using PC-ABS material. Process parameters influencing material consumption and manufacturing time have been identified. Experiments are conducted by using full factorial design of experiments and ANOVA is used for analyzing the results of experiments. Response surface methodology is used for carrying out the multi-objective optimization In order to set the optimal values of process parameters. It has found that:

1) Infill density affects the material consumption and manufacturing time. Lower infill density results in minimum material consumption and manufacturing time.

2) Layer thickness affects the manufacturing time and build orientation has impact on the material consumption. But effect of Layer thickness and build orientation on manufacturing time and material consumption respectively is lesser as compared to that of infill density.

3) In present work of multi-objective optimization, optimum results in terms of minimum values of material consumption and manufacturing time are predicted at setting of $20 \%$ infill density and $0.2582 \mathrm{~mm}$ of layer thickness with vertical build orientation.

For future work, optimization with objective of higher mechanical strength in addition to material consumption and manufacturing time of specimens can be carried out.

\section{REFERENCES}

Gibson, I., Rosen, D., Stucker, B. 2015. Additive Manufacturing Technologies: 3D Printing, Rapid Prototyping and Direct Digital Manufacturing, Springer-Verlag New York, 3-4 
Chadha, A., Haq, M., Raina, A., Singh, R., Penumarti, N., Bishnoi, M. 2019. Effect of fused deposition modelling process parameters on mechanical properties of $3 \mathrm{D}$ printed parts, World Journal of Engineering, 16/4

Pawar S., Dolas D. 2020. Experimental Investigation and Empirical Modeling of FDM Process for Tensile Strength Improvement, Innovative Product Design and Intelligent Manufacturing Systems, Lecture Notes in Mechanical Engineering. Springer, Singapore. https://doi.org/10.1007/978-981-15-2696-1_36

Sood, A., Chaturvedi, V., Datta, S., Mahapatra, S. 2011. Optimization of process parameter in fused deposition modeling using weighted principal component analysis, Journal of Advanced Manufacturing Systems, 10(2), 241-259

Panda, S., Padhee, S., Sood, A., mahapatra, S. 2009. Optimization of fuse deposition modelling (FDM) process parameters using bacterial foraging technique, Intelligent Information Management, 1, 89-97

Pawar S., Dolas D. 2019. Experimental Investigation of Process Parameters on Surface Roughness and Flexural Strength in Fused Deposition Modeling for PC-ABS Material, International Journal of Research and Analytical Reviews, Volume 6, Issue 1, 14-19

Rajpurohit, S., Dave, H. 2018. Impact of Process Parameters on Tensile Strength of Fused Deposition Modeling Printed Crisscross Polylactic Acid, International Journal of Materials and Metallurgical Engineering 12(2), 52-57

Motaparti, K., Taylor, G., Leu, M., Chandrashekhara, Castle, J., Matlack, M., 2017. Experimental investigations of effects of build parameters on flexural properties in fused deposition modelling parts, virtual and physical prototyping

Vishwas, M., Basavaraj, C., Vinyas, M. 2018. Experimental Investigation using Taguchi Method to Optimize Process Parameters of Fused Deposition Modeling for ABS and Nylon Materials, Materials Today: Proceedings, 5, 7106-7114

Ameen, W. Alahmari, A. \& Mian, S., 2021. Performance assessment of fused deposition modeling process. Journal of Engineering Research, 9(1), 200-213 